
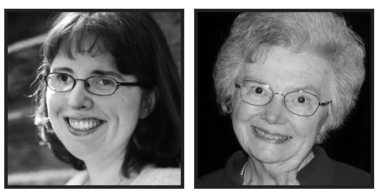

\title{
Portraits of High Potential-High Need Students: The Role of Teacher Inquiry
}

\author{
Ariel Baska and Joyce VanTassel-Baska
}

\section{ABSTRACT}

This article examines inquiry-based instructional approaches to working with students who have high potential, but also special needs. The article focuses on inquiry as the thread that weaves together a plan of instruction that has been successful for these students across the high school years in one teacher's classroom. Profiles of students are described with commentary as to the approaches employed with positive results. Commonalities of instruction, such as the use of metacognition, the use of acceleration, and the use of career counseling, are provided alongside student commentary where appropriate. A plan for the use of inquiry techniques in the classroom concludes the article.

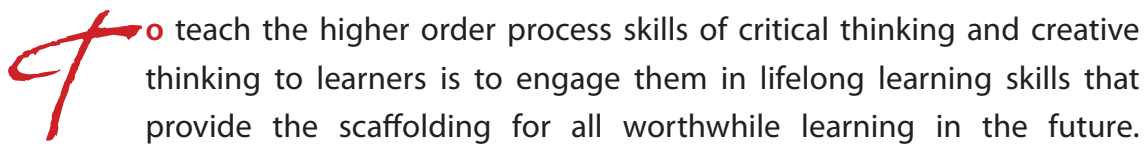
It is "teaching them to fish," not providing just one to be eaten for only a day. This constructivist approach to learning, however, requires similar approaches to be employed by the teacher, requiring long-term investment in learning new ways to think as well as teach.

Because higher order thought is not formulaic, it requires being open to the moment, asking the probing question at the right time, engaging students in the right activity based on when they most need it, and assessing levels of functioning with regularity. Inquiry-based teaching also requires teachers to provide students with useful models in order to have schema on which to hang their ideas. However, even useful models cannot be taught mechanistically; they must be 
thoughtfully applied and used idiosyncratically by learners so that the greatest benefits accrue. Finally, teachers must help students understand that real thinking is hard work, that it takes effort over time to improve, and that the outcome is frequently uncertain (VanTassel-Baska, 2013).

Artful inquiry as applied to the acts of teaching requires classroom teachers to attend to the needs of individual students and to apply accommodations that may vary from routine classroom practice. Thus, inquiry-based instruction may often be about asking the right questions about learners and experimenting with interventions that may work for them. This article features four profiles of special needs learners and documents the higher level questions that a thoughtful and reflective teacher asked in considering options in response to their needs. Where appropriate, it also features thinking schemas that promote student inquiry at the next level. It also presents a set of guidelines for inquiry that other teachers may use to generate similar results.

\section{Special Needs High Potential Learners}

Research suggests that certain gifted students have deficits in learning, attention, and socialization behaviors (Foley Nicpon, Allmon, Sieck, \& Stinson, 2011). Because of the dual exceptionality, these students experience great difficulty in negotiating learning pathways. Recent studies also suggest that the numbers of these students have almost doubled in the last decade (NEA, 2006). Research on twice-exceptional students, English language learners, and students of poverty (see Weinfeld, Barnes-Robinson, Jeweler, \& Shevitz, 2013; Angelelli, Enright, \& Valdes, 2002; Olszewski-Kubilius \& Clarenbach, 2014) demonstrates that they are often overlooked for gifted services because of a curriculum that does not play to their strengths. Alternatively, if identified, many of these special needs students underperform when faced with rigid curriculum structures that require narrowly defined behaviors and responses.

Because of the individual issues that minority, ELL, and twice-exceptional profiles present, it is often difficult for them to be identified for gifted or special education programs as these students are likely to develop compensatory strategies that mask either the disability or the talent. Educators many times see a flat profile that blends in with the crowd, because a student's giftedness is tempered by a learning disability, while at the same time, a student who should be identified for special education services will be denied because her giftedness lifts test scores and academic achievement just enough to fall within the "normal" range (Weinfeld et al., 2013). 
As a result, national data indicate that this population is not systematically programmed for, or even properly identified as, either gifted or disabled in some way. Researchers have also found that comorbidity is a common problem for these students, suggesting that learning disabilities often pair with ADD/ADHD, autism spectrum disorders, depression, anxiety disorders, and various other complicating variables such as minority status and low income that often make identification particularly difficult (Olszewski-Kubilius \& Clarenbach, 2014; Weinfeld et al., 2013).

The following profiles of four special-need students describe their characteristics, their needs, and the accommodations that have been successful with them. Because there is great heterogeneity among these students, there is no one strategy that can claim to work universally. Moreover, working successfully with these students requires access over years so that there develops a bond of trust between the teacher and learner and so that a teacher can come to better know student motivations and capabilities. Yet, the role of artful inquiry pervades these profiles as we examine the practice of a flexible teacher in asking the right questions about individual student needs.

\section{Methodology}

In constructing these student profiles, the teacher collected data from three different sources: written documentation on student behavior and performance, interviews with stakeholders, and observations in the classroom context. The teacher began research on each student by evaluating their IEPs (Individualized Education Plans) and 504 plans. After incorporating the knowledge gleaned from school documents into practice, she evaluated their efficacy, documenting what did and did not work best for each student. She also began interviewing the students themselves, their counselors, and their parents using a common set of questions. She carefully observed students behaviorally in class, in respect to their approaches to learning, taking notes. All data were analyzed qualitatively, using a content analysis model, looking for themes that best represented the commentary collected.

\section{Student A-Profile}

"Max" is a male student, diagnosed with ADD (attention deficit disorder), ED (emotional disability), and specific learning disability for dysgraphia, who was enrolled in my Latin I and Latin II classes. From my observations, Max is a generally 
happy student, who varies between extreme excitement and boredom and/or fatigue. He can be very charming, vocal, and attentive when engaged, but very often retreats into books when exposed to the same or similar material for more than 10 minutes. He also seems fatigued on a daily basis and will usually nod off at least once, but with focused attention of the teacher and specific direction, he seems to come alive. $\mathrm{He}$ is a highly verbal student who excels in presentations and classroom discussions, but can't express his thoughts in writing easily, due to his dysgraphia and poor organizational skills. His parents do not feel that they can adequately explain Max's academic difficulties. They theorize that he is a "bored gifted student with a possible mood disorder." Max says of himself, "I know I'm smart, but I only realize that outside of school, when I'm making connections to the real world. School is so far from reality... I can't play the game [of school]."

\section{Student A-Accommodations That Work}

Teacher questions: What specific help does Max need to function in daily learning situations? How can I evaluate the options available?

Because Max often does not pay attention to the details of what he reads, he should have test directions read to him or instructions given to him, rather than reading them to himself. In other settings, his reading and writing needed to be structured with graphic organizers wherever possible. Max tends to become overwhelmed by assignments and spends more time thinking in tangential topics, rather than focusing his thoughts on the topic at hand. He needs a clear road map or table of contents to help him in reading English passages on history or mythology, and a similar road map to help him outline his thoughts or translation when he needs to write.

Teacher questions: What supportive technology does Max need to augment his learning? What approaches may he use to self-assess? How will I know he has made progress?

Ideally, Max would have a computer on hand at all times to help him take notes, since he can type much faster than he can write with a paper and pen. Unfortunately, given his history of losing school-supplied Neos and other electronic equipment, the school district will no longer provide him with one, nor are his parents inclined to purchase one. As a result, I encouraged him to invest in a small recording device that he wore around his neck to record lectures and class discussions for future reference. 
Max also needs further opportunities for metacognition to help him think about his own thinking process. He became deeply engaged in the conversation we had about how he thinks and how he learns best, and immediately wanted to test out his own hypotheses. He needed to be aware of himself on this level, and spend time evaluating his own learning.

What do I know?
What do I need to know?
How can I find out?
What have l learned?

Fig. 1: Thinking schema for Max

Teacher questions: In what ways can Max become more motivated to learn? How might he regulate his emotions to channel them for productive learning behaviors?

Like many gifted students, Max suffers from chronic boredom in many of his classes. He knows that he is very bright, and feels uninterested in doing "busy work." Since Max can't control either when a teacher will give him this kind of work, or when activities in class will fail to engage him, the problem of motivation is best addressed affectively, rather than cognitively. Max should continue to reflect on his own feelings and emotions and evaluate when they are or are not keeping him from understanding the material. He has admitted to me that sometimes he takes pride in not listening and still being able to understand the material, though he also admits that he hasn't had that particular sensation in a while. He needed to become more aware of these sensations and feelings as they happen, and begin the process of learning to regulate them when possible.

\begin{tabular}{|c|}
\hline Use of emotional intelligence activities \\
\hline Use of bibliotherapy \\
\hline Use of small group discussions with peers \\
\hline
\end{tabular}

Fig. 2: Activities 
Teacher questions: What activities will demonstrate Max's progress to himself? How may his interests be used to address his self-concept?

Max also worked on developing his strongest skills and abilities through acting and presenting where possible. He is a student who needs to be able to develop his strengths and skills and use those to access new information wherever possible. He desperately needs to know that he is developing and growing - this is key to his self-concept.

Ideas for Max in respect to self-knowledge might include the following approaches:

1. Pre-assessments that allow students to consider what they already know on a topic, and discuss what and how they'd like to learn more.

2. Exit tickets/surveys regarding what confused them about a reading (whether grammar sections, particularly after assessments [what did I do to study that worked, what didn't?]).

3. Keep sticky notes on hand for students to write down study questions and identify themes while working on translations, reading articles, and so forth.

4. Model good strategies-discuss how you know when you are done with a translation or paper.

\begin{tabular}{|} 
What new and important learnings have I gained \\
in the past 30 days? \\
How have they made an impact on my thinking?
\end{tabular}

Fig. 3: Monthly questions for Max to consider

\section{Student A-Student's World Language Trajectory}

"Max" completed two years of Latin before deciding to switch to Spanish for two years, where he says his work with the Latin language helped him learn to read the Spanish language more fluently, and helped with the "organization of the language"in particular, vocabulary and grammar.

\section{Student B-Profile}

"Laura" is a female student who was born deaf, and uses American Sign Language (ASL) as her first language. Laura is fully mainstreamed in the public school setting, accessing all of her classes with the aid of interpreters who translate for her in the classroom. She has excellent work habits in all of her classes, except for math, which is 
her weakest subject area. She is an avid reader, who read many college-level texts in middle school, and continues to express herself well both orally and in writing. She comes from a low-income family that cannot afford to send her to college; thus procuring college scholarships is an important consideration for her.

Teacher questions: What strategies can be used to reach Laura regularly, rather than intermittently? How can her daily performance become more steady across subject areas?

While Laura is a student who regularly shines in class, she has difficulty accessing some areas of the curriculum due to her disability, and can sometimes shut down, either by retreating into a book or, at times, becoming defiant. She responds well to stories about people, facts, and details, and translates literature at a higher level than most of her peers, but often has difficulty understanding the finer points of grammar and will disengage from the material at hand if it is not represented visually.

In Latin, she experiences difficulty relating to the "sonics" of poetry, such as meter and figures of speech. At one point, she insisted that I could not expect her to learn how to scan poetry due to her disability, and that she simply couldn't, no matter what. Scansion refers to how many short versus long vowels there are in a line of poetry, which affects how it is pronounced, and can affect interpretations of the grammar, and therefore, how a line can be translated. Because scansion is in the program of studies and on the AP exam for Latin, Laura could not be excused from this material. Because she couldn't hear the vowel sounds, she didn't believe she could evaluate them, but by working individually with her and a like-minded interpreter, and giving her a list of rules about how to tell a long vowel from a short one, she was able to learn scansion better than her hearing peers.

Individualized assistance with rules and procedures
Practice with difficult material
Targeted focus on a narrow skill set
Visual display of material to be learned

Fig. 4: Strategies for Laura 


\section{Student B-Accommodations That Work}

Teacher questions: What is the role of visual strategies in helping Laura learn? How do multiple strategies, used together, help Laura?

This anecdote taught me that Laura could learn anything in my classroom, and learn it well, as long as she was provided a list of procedures to follow, in a step-by step process. She needed the structure and visual confirmation of the rules for both scansion and other grammar points. I knew that all information needed to be presented to her visually on some level, but never realized how important the "formula" would be for her.

As with any deaf student, graphic organizers and organized notes are important accommodations, because they allow her to process the material in structured ways. She also benefits from use of the SmartBoard, as it allowed me (and the students) to mark up the text we were studying at any given time, so that she could see our discussion unravelling on the board, not just through her interpreter's hands.

\begin{tabular}{|c|}
\hline Mapping discussions visually \\
\hline Graphic organizers that represent content to be learned \\
\hline Outlining of important content to be learned \\
\hline
\end{tabular}

Fig. 5: Further strategies for Laura

Teacher questions: What communication tools might aid Laura? What models of discussion might teachers use?

Like Max, Laura can suffer from chronic boredom with school, due to her intellectual ability which sets her apart from her peers, and at times, because of the difficulties of communication with others. To succeed, she needs teachers who will structure conversation in class, through a Socratic Seminar or other means, and engage with her in discussion, and make connections with any of her various intellectual interests. 
Teacher questions: What strategies might aid Laura in considering her career path? What opportunities might be useful?

She also requires guidance regarding her future career path. She says,

I don't have definite plans for the future when it comes to jobs, but perhaps I'll be a history researcher, translator of works written in foreign tongues, or a scholar in classical history or languages such as Hebrew, Latin, or Greek.

Working with students like Laura on future career choices and how best to pursue them is crucial, as sometimes accessing that information can be difficult. Creating connections to real-world job opportunities can be crucial in establishing identity, preparing students, and empowering them. It would be helpful if the school could provide internships or mentorships for such students, contexts where they had contact with real-world professionals in fields of interest to them.

\section{Student B-Student's World Language Trajectory}

"Laura" completed five years of Latin, while concurrently enrolled in Spanish for two years. She attended the prestigious Governor's School Latin Academy over the summer after her junior year, with the aid of interpreters. She also won numerous awards related to her study of Latin, from gold medals on the National Latin Exam, to scholarships offered by the National Junior Classical League. She described her time in the Latin program by saying:

Truly, the period which I spent in the Latin program... was a time of great intellectual flourishing in my life... [Latin] class was always the eye of the storm, so to speak, in the barren desert of my formal education... Indeed, my time in the Latin program cast a luster on that part of my life which had been utterly shorn of meaningful accomplishments...

\section{Student C-Profile}

"Ryan" is a male student, diagnosed with ASD (autism spectrum disorder), ED (emotional disability), and a specific learning disability for dysgraphia. He is always eager to share his knowledge and participate in class in any way that he can. He is highly motivated in his classes, but when frustrated, he tends to react very strongly. He sometimes raises his voice, or uses inappropriate tone or language in reaction to certain triggers. He has been a victim of bullying in the past, and is very concerned with 
the perceptions of other students. Ryan can become embarrassed easily. He also is very worried about equity in the classroom, and will immediately stand up for himself or any other student if he perceives something as unfair.

Teacher question: What approaches might be used with Ryan that address his needs, but also play to his strengths?

Ryan suffers from problems with organization, and with his motor coordination, particularly in respect to writing. He often has difficulties finding homework or notes if they have been hand-written, and will become frustrated looking for things in his backpack or binder, which can be a trigger for him. Ryan also becomes frustrated when teachers don't recognize his talents, either because of his difficulties with handwriting or social communication. He excels in his scientific knowledge of various species, and brings outstanding vocabulary skills to the Latin classroom, in addition to many interesting scientific connections. Ryan is deeply focused on a few subjects that are of interest to him. He talks a lot about certain characters from teen fiction and comic books that appeal to him, but he is most passionate about animals.

\section{Student C-Accommodations That Work}

\section{Teacher question: What technology works for Ryan?}

As for many students, the use of a laptop was crucial for Ryan. The laptop allows him to access saved homework assignments, e-mail his homework and classwork assignments, and access helpful applications and websites that extend his knowledge on certain topics. The laptop also allowed him to learn a new way of thinking about organization of files, and he began scanning important papers into .pdf files on his computer.

Use of web-based research on a scientific issue to stimulate interest: evolutionary biology, genetic manipulation, or animal behaviorism

Desktop graphic organizer that asks basic questions about the day

Fig. 6: Strategies for Ryan 
Teacher questions: What strategies might teachers employ to assist Ryan's progress? How can thinking about a career help Ryan at this stage?

Ryan requires a good amount of teacher direction to stay on task if other students in the room are talking, as they are a significant source of distraction for him. However, at the same time, he cannot bear to complete work outside in the hallway or in the neighboring computer lab, as that separates him from peers. This caused me considerable frustration until I realized that he needs to learn to organize his thoughts, his time, and his work in highly structured ways as a part of a regular routine. By asking him to work on a separate graphic organizer, separated out by how much time he has to complete an assignment and giving specific time requirements for each section, I've found that other people are much less of a distraction for him, as his work becomes a race against the clock. I also found that helping him to organize his binder and his backpack aided his concentration as well.

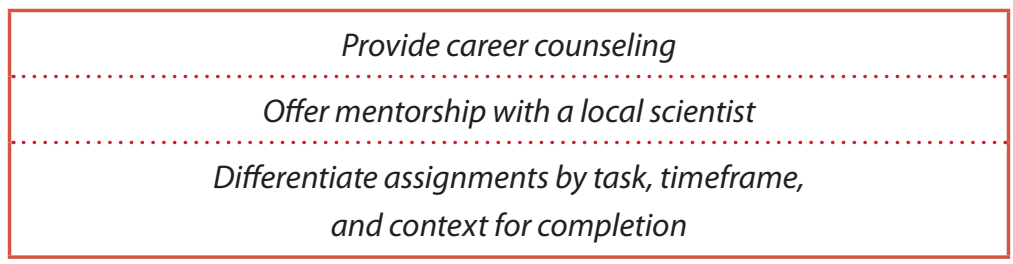

Fig. 7: Further strategies for Ryan

At the National Association for Gifted Children Conference in Denver, Colorado, I had the good fortune to share a conversation about Ryan with Temple Grandin. Given her own experiences and her passionate interest in animals, I asked her advice as to how to help Ryan. Her advice was clear-cut: get him as much career advice as possible, and make sure he is counselled in directions that will help him become a strong candidate for jobs. As a result, Ryan visited the Career Services center at school once a month in his junior and senior years, doing research on what careers would be appropriate, and familiarizing himself with the requirements.

\section{Student C-Student's World Language Trajectory}

"Ryan" completed his third year of Latin in his senior year, which he hopes will further his interest in working with animals on a scientific level. 


\section{Student D-Profile}

"Mitch" is a male student, and the only one from this study formally identified as gifted. He has been diagnosed with ASD (autism spectrum disorder) and ED (emotional disability) due to his selective mutism. He is an excellent writer with outstanding verbal skills that put him far above his peers in respect to his use of vocabulary, critical thinking skills, and maturity of thought. Mitch completes all assignments and assessments with the top grades in the class. Mitch is very reluctant to speak, even in situations where he has much to say on a topic, due to social anxiety. When he does speak, he speaks very quietly, and can often be misheard or misinterpreted. Many teachers have underestimated his skills, based on his problems with communication. Sometimes his problem is comingled in teachers' minds with English not being his native language.

While his peers respect his skills and talents, he has few friendships at school. His older peers from Latin class and Latin Club have been his social network at school, after school, and at extracurricular competitions. His mother believes very strongly that Latin helped him to grow in his social development. Mitch is very interested in social issues, and can make excellent arguments for his stances. He feels very strongly that he would like to work for a non-profit organization.

\section{Student D-Accommodations That Work}

Teacher questions: What is Mitch's preferred learning context? What grouping arrangements in the classroom may support Mitch?

One of the more important accommodations for Mitch was allowing him to work independently. I found quickly that he shut down in group work situations as soon as he had completed his part of the task. At first, I suspected this was due to his social anxiety. However, further inquiry revealed that he didn't feel challenged when asked to work as a part of a group, doing only one component of a project. He far preferred being able to delve into all aspects independently. He also needed (on occasion) to give presentations to me after school, or present information in a different format that wasn't as stressful for him as an oral presentation.

\begin{tabular}{|} 
Differentiation of presentation options \\
Flexible grouping that allows for independent work \\
Acceleration of content, based on diagnostic info
\end{tabular}

Fig. 8: Strategies for Mitch 
Teacher questions: How can content acceleration aid Mitch in his path toward advanced learning? How might that be accomplished within the school context?

Acceleration has been the most important accommodation for Mitch. In Latin I, I took far too long to recognize his gifts, and could not do much for him beyond independent projects and alternative assessments. In Latin II, he began work on advanced Latin III material, and was able to pass the Latin III final exam with flying colors. At his request (and after a little teacher investigation), Mitch skipped Latin III and jumped into AP Latin as a sophomore. His mother felt that the acceleration may have made it more difficult for him to make friends in class, but I argued that he needed to be with his intellectual peers, engaged with higher level material. He scored a 5 on the AP exam, the highest level possible, demonstrating that he was more than ready to engage in the advanced level of study mapped out for him.

\section{Student D-Student's World Language Trajectory}

"Mitch" is currently enrolled in his sixth year of Latin, an independent study course designed especially for him. He has earned perfect scores on every National Latin Exam, and won various awards from the National Junior Classical League. Of his work with the Latin program, his mother writes the following:

I am most grateful for the transformation that I have seen in my son, in terms of his participation in Certamen... [which he kept as] his top priority... for the last three years, which in itself is nothing short of miracle, considering how limited his social world has been all of his school life since first grade; his coming out of the comfort zone to be in these team competitions has been possible only through the deep trust that the teacher has built within him. No therapists or counselors have ever been able to help him take such risk to be out in [the] public eye on a regular basis.

\section{Commonalities Across the Four Profiles}

According to research, special needs students are under-identified for gifted services, at a ratio as high as one in two. Yet, in the case of three out of four of these students, identification came about through a challenging curriculum. Curriculum that forces students to think in complex ways and at an accelerated pace brings forth behaviors overlooked in other classrooms. Moreover, the interaction that occurs between teacher 
and learner in daily interactions across a four-to-five-year period clearly accentuates the role of inquiry as a primary process to spur motivation and performance.

While all four of these students differ in respect to their needs and talents, there are commonalities among them, and perhaps among many special need students. All of the four need interventions that are both academic and social-emotional. On the academic side, each of them required different forms of acceleration, either within individual assignments or for a whole grade level. They also needed to work on metacognitive skill sets, such as planning and organizing as well as reflecting on their own learning. At the social-emotional level, these students needed to learn to take academic risks and to have an advocate who would be available to discuss coping mechanisms and special problems that arise in the academic sphere of their lives. At the conative level, these students needed to use their motivation in productive ways. They also needed career guidance provided by a counselor or career services specialist, as well as careeroriented advice and help with relevant skills from all teachers.

Long-term planning, for example, was a critical need among these students-to be able to see a few years ahead, rather than just a few months. The following approaches may assist other students with this process:

1. Embrace multipotentiality-encourage, don't limit student interests and new directions for learning.

2. Share information about planned education/career path and current destination.

3. Discuss interview skills, job skills, and self-advocacy.

4. Locate peers and mentors for students at varying stages of school/career/life.

5. Encourage career/school research by teaming up with Career Services or guidance office.

Teacher characteristics these students responded to also varied, but some were common among all. They all appreciated teachers who were open to trying new things, especially if student-selected or suggested. One student said, “Even if a strategy doesn't work, at least it lets you know they care enough to see if it does." Another said that he preferred teachers who were willing to teach to his strengths, "since very few teachers see me for who I am if they teach me in [my area of weakness]." Another desirable teacher trait was patience, helping them work through their difficulties or disabilities, and particularly supporting them when they failed at something, refusing to let them quit. These students all commented on the need for a teacher who will help them succeed, allowing them freedom of choice wherever possible and focusing on what works for them as learners. 
In each of the four portraits cited, the teacher provided the following scaffold to promote higher level inquiry in the students:

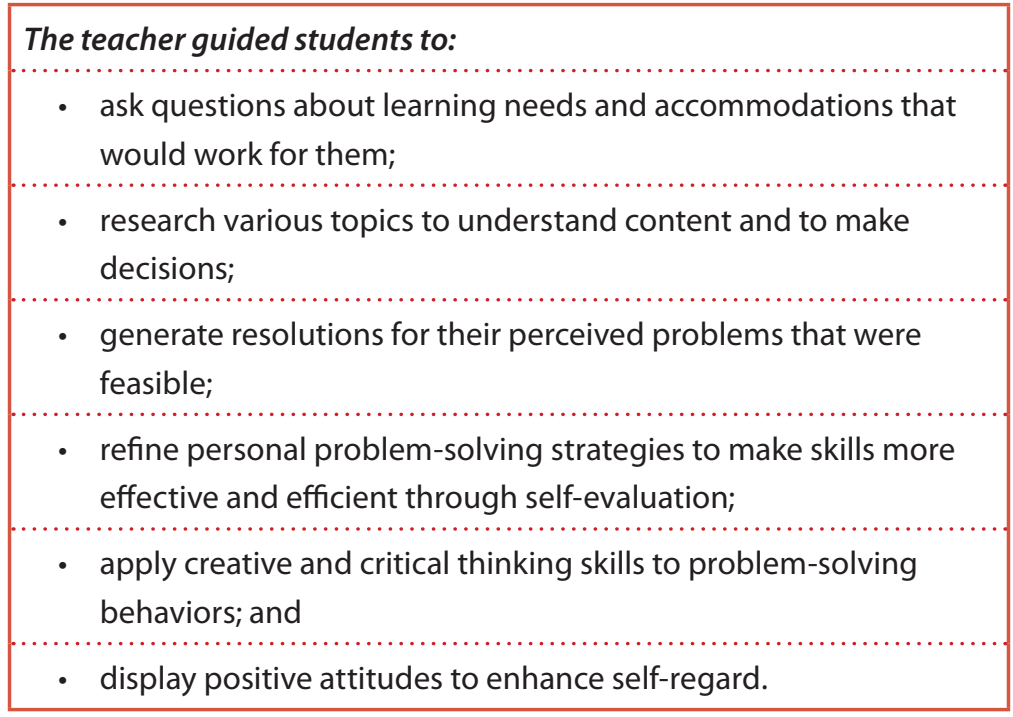

Fig. 9: Inquiry-based learning

All of these outcomes are simultaneously achievable within a learning situation where students engage directly with their own learning problems in which they take charge of its pace, style, and organization. Autonomy in learning becomes the goal alongside the specific content and skill-based learning to be mastered. In the four portraits highlighted, one teacher provided this scaffolding across four years, resulting in enhanced performance at high levels for the special needs students under her care.

\section{Action Research}

Just as inquiry drove the learning of the four students highlighted in this article, so too the urge to know drove the teacher's desire to ask questions and pursue strategies that were effective for these students. Thus, the inquiry process has meaning at both the student and teacher level, with the teacher as constructor of a classroombased study that yields important information on what works with special needs students. Teachers' use of data available to them when carefully organized, analyzed, and evaluated, can provide important insights into advancing the learning of students, especially those who present challenging profiles. 


\section{Conclusion}

This article has presented profiles of four special needs learners who exhibited high potential, but lower general achievement than expected at the beginning of their high school years and traces their journey in being provided challenging curriculum and inquiry-based instruction across four years of high school. It also focuses on the role of question-asking in the teacher's repertoire that framed the interventions which elevated student thinking and motivated them to pursue their passions. The article concludes with a commentary on their performance and the commonalities in their accommodations in school that were successful.

\section{References}

Angelelli, C., Enright, K., \& Valdes, G. (2002). Developing the talents and abilities of linguistically gifted bilingual students: Guidelines for developing curriculum at the high school level. Storrs, CT: National Research Center on the Gifted and Talented.

Foley Nicpon, M., Allmon, A., Sieck, R., \& Stinson, R.D. (2011). Empirical investigation of twice exceptionality: Where have we been and where are we going? Gifted Child Quarterly, 55, 3-17.

National Education Association. (2006). The twice-exceptional dilemma. Washington, DC: Author.
Olszewski-Kubilius, P., \& Clarenbach, J. (2014). Closing the opportunity gap: Program factors contributing to academic success in culturally different youth. Gifted Child Today, 37(2), 103-110.

VanTassel-Baska, J. (2013). From creativity education to innovation education: What will it take? Chapter in L. Shavinina (Ed.) The Routledge international handbook of innovation education (pp. 111-127). New York: Routledge.

Weinfeld, R., Barnes-Robinson, L., Jeweler, S., \& Shevitz, B. (2013). Smart kids with learning difficulties. Waco, TX: Prufrock Press. 


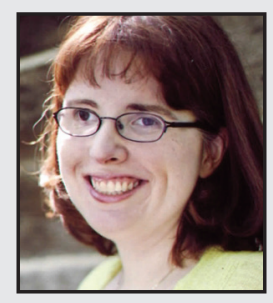

Ariel Baska teaches all levels of Latin in Fairfax County Public Schools. She received her Bachelor's degree in Classics from the College of William and Mary. She received her Master's degree in Curriculum Studies with an emphasis in Gifted Education at George Mason University. She was the 2015 recipient of the A. Harry Passow Award and Scholarship from the National Association for Gifted Children, in recognition of her work with gifted students in the classroom. She has co-written a Latin curriculum guide for elementary and middle school gifted students, entitled, Ancient Roots and Ruins, in 2013.

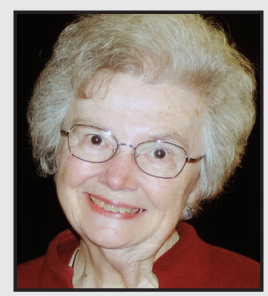

Joyce VanTassel-Baska is the Jody and Layton Smith Professor Emerita of Education and former Executive Director of the Center for Gifted Education at The College of William and Mary in Virginia where she developed a graduate program and a research and development center in gifted education. She also initiated and directed the Center for Talent Development at Northwestern University. Dr. VanTassel-Baska has published widely including 29 books and over 550 refereed journal articles, book chapters, and scholarly reports. Her major research interests are on the talent development process and effective curricular interventions. She holds BA, MA Ed., and EdD. degrees from the University of Toledo. 